\title{
O marketing digital na educação a distância: estratégia em rede social e a resistência à educação a distância identificada na América Latina
}

Leonardo Viana, Fundação Cecierj/Associação Ibero-Americana de Educação Superior a Distância, Brasil Fabiane Proba, Fundação Cecierj/Associação Ibero-Americana de Educação Superior a Distância, Brasil

Resumo: O presente artigo propõe abordar como a aplicação do Marketing Digital estratégico pode contribuir na tentativa de reduzir a resistência sobre a Educação a Distância (EaD), identificada por autores como Gomes (2008), Moore (2007) e Belloni (1999). Tal resistência é fruto de uma percepção negativa sobre esta modalidade de ensino, como ocorre na América Latina. Foi utilizado como objeto de estudo as ações de Marketing Digital da Fundação Cecierj - Centro de Ciências e Educação Superior a Distância do Estado do Rio de Janeiro (instituição governamental brasileira, referência em EaD), em seu Facebook (facebook.com/cecierj), na tentativa de reduzir a resistência ao ensino a distância. Referências bibliográficas em Marketing e EaD foram utilizadas como metodologia para abordar a importância do estudo de estratégias para a tomada de decisões em Facebook corporativo, assim como a relevância da observação histórico-cultural quando identificada necessidade institucional de aceitação de uma ideia. O Marketing atua na formação do pensamento coletivo (Moscovici, 2002) e o Facebook, rede social amplamente utilizada na América Latina, como ferramenta, tem o potencial de formar opinião, o que justifica sua abordagem neste trabalho no mecanismo de difusão de ideias e formação de capital social (Kotler, 2010). A finalidade da pesquisa não é confirmar se houve mudança na percepção da Educação a Distância por parte do público do Facebook do Cecierj, a partir das ações estratégicas de Marketing Digital, e sim fundamentar sua aplicação na tentativa de alcançar a redução da resistência à EaD.

Palavras-chave: marketing digital, educação a distância, resistência

\begin{abstract}
This paper aims at approaching how the application of strategic Digital Marketing can contribute in an attempt to reduce the resistance to Education at Distance (ED), identified by authors as Gomes (2008), Moore (2007) and Belloni (1999). This resistance is the result of a negative perception of this type of education, as it happens all over Latin America. It was used as object of study the Digital Marketing actions of Cecierj Foundation - Center for Science and Higher Distance Education of the State from Rio de Janeiro (a Brazilian government institution, in reference to ED), on its Facebook page (facebook.com/cecierj), in an attempt to reduce the resistance to education at distance. References in Marketing and ED are used as a methodology to approach the importance of studying strategies for making decisions on corporate Facebook, as well as the importance of historical and cultural observation when the institutional need for the acceptance of an idea is identified. Marketing actions in the formation of collective thought (Moscovici, 2002) and Facebook, social network widely used in Latin America, as a tool, have the potential to form an opinion which justifies its approach in this work with the ideas diffusion mechanism and social capital formation (Kotler, 2010). The purpose of the research is not to confirm if there was a change in the perception of Education at Distance by the public of Facebook Cecierj, from the strategic actions of Digital Marketing, but to support its application in an attempt to achieve a reduction of the resistance to ED.
\end{abstract}

Keywords: Digital Marketing, Education at Distance, Resistance

\section{Introdução}

Om a eclosão das novas tecnologias, o Marketing no ambiente digital ganha posição de destaque e mostra-se eficaz cada vez que aplicado como estratégia de comunicação. Entender o que pensa seu público-alvo e os porquês de suas ideias tem papel fundamental para o sucesso na transmissão da mensagem que envolve o trabalho na área. É o que se pretende mostrar com o estudo de caso do Facebook da Fundação Cecierj, órgão governamental de Educação a Distância, do Estado do Rio de Janeiro - Brasil.

Revista Internacional de Tecnología, Ciencia y Sociedad

Volumen 4, Número 1, <http://tecnociencia-sociedad.com>, ISSN 2530-4895

(C) Global Knowledge Academics. Leonardo Viana, Fabiane Proba

Todos los Derechos Reservados Permisos: soporte@gkacademics.com

Republicado de Revista Internacional de Tecnología, Conocimiento y Sociedad 4(2), 2015 (pp. 129-144) 
Para tal, o artigo aborda as origens de uma aparente resistência à EaD na América Latina, embasada pela concepção de estudiosos do assunto, como Gomes (2008), Moore (2007) e Belloni (1999). Tal quadro é gerado por percepções negativas da metodologia de ensino, como motivadas pelo histórico de cursos de baixa qualidade e baixo valor acadêmico e por dificuldades em se lidar com recursos de informática.

Também é razão para a resistência o fato de a Educação a Distância requerer do aluno uma autonomia a qual não está acostumado no modelo tradicional, em que o professor é figura central no processo de ensino-aprendizagem. A visão desfavorável à EaD parte, principalmente, de pessoas que nunca tiveram contato com o metodologia, conforme Gomes (2008).

Com base nestes dados, o Marketing Digital do Facebook da Fundação Cecierj atua de modo a tentar minimizar a potencial expectativa negativa daqueles que não conhecem o método a distância de ensino e alterar possível percepção desfavorável por parte dos que já tiveram contato.

Para isso, vale-se de referências bibliográficas da área como Kotler (1998), Recuero (2009) e Lin (2001), na adoção de estratégias do modelo de Marketing 3.0, que prima por uma interação humanizada com o público, sensível aos seus desejos, anseios e necessidades.

Nos trabalhos, destacam-se três pilares básicos: o Marketing Colaborativo, em prol de voz ativa para os participantes da página; o Marketing Cultural, com ações que envolvem o público-alvo pelas abordagens afinadas com o contexto político e sócio-cultural de cada momento; e o Marketing Espiritual, que atua com sensibilidade a questões gerais que influenciam o pensamento do público, assim como àquelas singulares, inerentes a cada indivíduo.

Esta atenção personalizada junto aos integrantes da rede social chama-se Nanotarget, uma técnica de Marketing de Relacionamento, cujas teorias são igualmente colocadas em prática no espaço virtual específico, objeto deste estudo.

\section{A Educação a Distância e a resistência ao modelo de ensino}

\subsection{A Educação a Distância}

A Educação a Distância (EaD), por definição, segue as seguintes características, de acordo com Belloni (1999): separação física entre aluno e professor, uso de técnicas adequadas à comunicação entre docentes e alunos, e controle do ritmo de aprendizado por estes últimos.

Em comum com o autor, Costa e Franco (2005) acrescentam que a EaD hoje se fundamenta na utilização de meios técnicos de comunicação como e-mails, Internet, áudios e videoconferências. É um método economicamente vantajoso e com possibilidade de atender a grande número de estudantes, principalmente quando baseado em tecnologias como Internet atualmente.

Moore (2007) acrescenta que quando há aprendizado em lugar diferente do local de ensino, sendo este planejado e construído por meio de tecnologias apropriadas, define-se, assim, metodologia a distância. $\mathrm{O}$ autor também ressalta que o aprendizado em educação não é algo que se aprende a esmo, ou seja, quando se absorve conteúdo na Internet não significa que houve a $\mathrm{EaD}$, pois o apren- dizado de que trata o autor é intencional, organizado e orientado.

$\mathrm{Na}$ mesma linha, Zerbine et al. (2006) expõe que a Educação a Distância exige do aluno um planejamento sistemático, a fim de que este possa ter bom aproveitamento nos estudos, com adequação às características de comunicação assíncrona e distância espacial, próprias da modalidade de ensino. Tal metodologia na América Latina é cercada de resistência, gerada por percepções negativas sobre a modalidade de ensino. Fatores que as motivam são abordados a seguir.

\subsection{As raízes da resistência sobre a EaD na América Latina}

A resistência que recai sobre a Educação a Distância tem origem em percepções negativas a partir de questões histórico-culturais observadas neste estudo. Para Cavalcanti (2007), na América Latina, tal visão desfavorável à metodologia é um dos fatores responsáveis pela $\mathrm{EaD}$ ainda não ter despontado como solução para os problemas latino-americanos de inclusão digital e democratização educacional, apesar de agregar aspectos positivos da globalização. 
Especialmente em países da América Latina, a EaD mediada pelas novas tecnologias, ainda não está disponível para as massas, pois sua implantação esbarra em políticas educacionais burocratizadas, necessidade de investimentos pesados por parte das instituições e governo e, principalmente, na resistência cultural por parte de alunos e meio acadêmico. (Cavalcanti, 2007)

Segundo Belloni (1999), a Educação a Distância e sua implementação não são a vitória da democratização do ensino aberto, como sugere Niskier (1999) para o Brasil, por exemplo, e sim uma forma barata de educação, inspirada em modelo de linha de produção fordiana, que fere a estrutura artesanal do ensino e visa atingir as massas, no que o autor intitula de "industrialismo instrucional".

Esta é uma crítica à EaD relacionada a uma mecanização do ensino em uma área na qual a humanização é relevante. Nesta linha, para Belloni, o ensino a distância, fruto da tecnologia moderna, é uma maneira que governos e empresas têm de economizar financeiramente e melhorar suas estatísticas de oferta de educação de nível superior.

A Educação a Distância é alvo de resistência na academia. Para Correa (2009) e Ferreira (2010), as tentativas frustradas de implantação da modalidade prejudicaram a sua imagem como aconteceu no Brasil, assim como os cursos de baixo valor acadêmico e voltados essencialmente para público de baixa renda, como os de eletrônica básica, costura, mecânica e supletivos.

Assim, de acordo com os autores, resiste-se à modalidade por atribuir incompetência àqueles que obtiveram o diploma por correspondência. Adjetivos como "picaretas", "incompletos", "balelas" e "superficiais" são associados a cursos de Educação a Distância. A baixa qualidade associada a tais cursos na conceituação do latino-americano em geral leva o aluno a conjecturar que sua metodo- logia é mais fácil do que a do sistema convencional.

Porém, ao cursar a modalidade a distância, verifica que ocorre exatamente o contrário, que ela exige mais dedicação e disciplina do estudante. Esta frustração é responsável por $51 \%$ das desistências no ensino a distância no Brasil, segundo Pesquisa da ABED (2010) - Associação Brasileira de Educação a Distância.

Para Schlickmann et al. (2009), a modalidade tem caráter de "segunda chance" para pessoas que não tiveram tempo propício para estudar ou estão inseridas no mercado de trabalho, buscando qualificação, mas, sem horário para frequentar salas de aula, aceitam se submeter à metodologia que consideram de pior qualidade comparada ao ensino presencial. Neste contexto brasileiro, a EaD se enquadra na concepção de um tipo de educação barata e massiva e não como opção de ensino.

Nos países pobres, a educação a distância aparece como solução de emergência para problemas educacionais, enquanto nos países ricos, ela vem contribuindo para melhoria da qualidade do ensino presencial em todos os níveis. Em todos os casos, a inovação tecnológica está no centro dos processos de educação no intuito de torná-los mais aptos a responder às demandas sociais do século XXI. (Belloni, 1999, p.20)

Outro ponto gerador de percepção negativa ao método a distância de ensino, para Correa (2009) e Ferreira (2010), se refere ao fato de que, ao prever a autossuficiência do aluno, a metodologia produz um deslocamento para este do foco de todo o processo de ensino-aprendizagem, ao contrário do que se observa no ensino tradicional, em que o professor é o detentor da informação.

Desta forma, o docente perde o poder e o controle da centralidade do ensino, o que pode gerar resistência a esta modalidade de educação por parte dos alunos, alunos em potencial e professores. Por parte dos alunos e alunos em potencial, a resistência pode estar ligada a uma questão cultural, de tradição do modelo presencial, e por pouca familiaridade com a EaD. Por parte dos professores, o motivo pode ser o esvaziamento do controle junto aos alunos e o receio de demissões, frente ao modelo que requerer menos integrantes no corpo docente quando comparado ao presencial.

Somado a estes motivos que levam à resistência ao modelo, Zwicker e Reinhard (1997) destacam que questões relacionadas à informática, inerentes ao ensino via computador, como infraestrutura, interfaces, manutenções e atualizações de softwares, e a dificuldade em lidar com 
elas, corroboram para o aparecimento da resistência. Tal fator também é abordado por Gomes (2008) no decorrer deste artigo.

\subsection{As principais razões da resistência}

Os motivos observados neste estudo que levam à resistência à $\mathrm{EaD}$ são percepções negativas advindas, em síntese, de massificação e mecanização do ensino, tentativas frustradas de implantação de cursos, cursos de baixo valor acadêmico e baixa qualidade, frustração ao perceber que a metodologia é mais exigente para o estudante do que o esperado, deslocamento do foco do professor para o aluno e dificuldade com recursos de informática.

Com o esquema a seguir (Figura 1), Gomes (2008) desenvolve uma base teórica sobre a resistência à Educação a Distância, a partir daqueles que já tiveram contato e/ou fizeram curso de $\mathrm{EaD}$, mostrando as dimensões da resistência inerentes ao indivíduo (lado esquerdo da figura) e as dimen- sões influenciadas pelo ambiente (lado direito).

O autor aplica sua teoria em universidades corporativas (UC) no Brasil, que são instituições de ensino técnico e superior, em nível de graduação e pós-graduação, vinculadas a empresas públicas ou privadas, com objetivo de oferecer cursos específicos para seus funcionários, geralmente virtuais, sintonizados com os interesses da empresa. Veja Figura 1:

Figura 1: Dimensões da resistência em EaD para UC

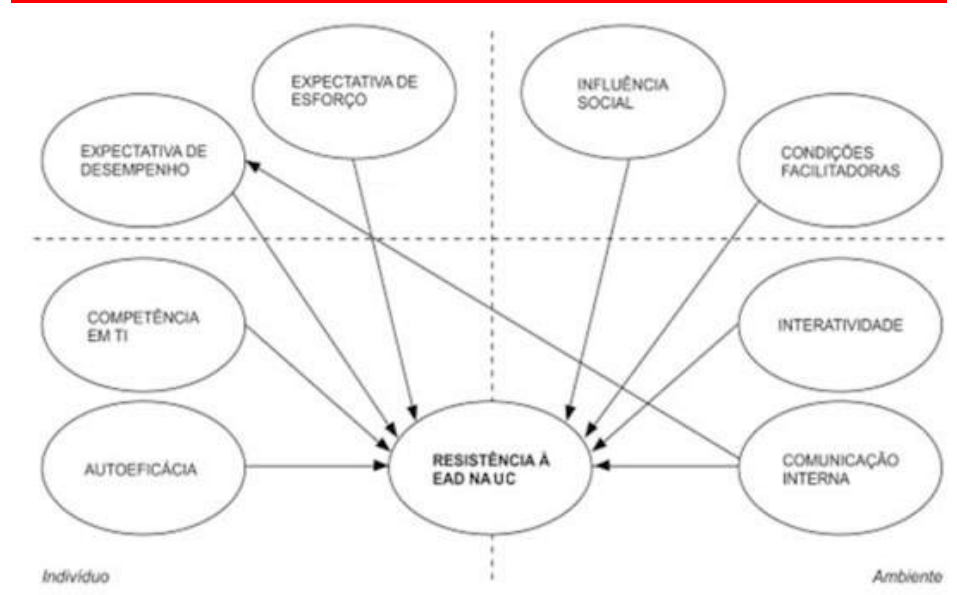

Fonte: Gomes, 2008.

Apesar de a Figura 1 se referir às dimensões da resistência para quem já teve contato com EaD, Gomes (2008) comenta que as visões desfavoráveis sobre a metodologia de ensino partem, principalmente, daqueles que nunca vivenciaram a experiência de ser aluno em curso ofertado nesta modalidade.

Baseado neste dado, Viana (2011), em uma adaptação à teoria de Gomes, observou as principais razões que levam à resistência na referida teoria, ao eliminar as variáveis que motivam a percepção negativa, relacionadas ao ambiente (veja Figura 2), já que a ambiência não se aplica àqueles que nunca tiveram contato ou cursaram $\mathrm{EaD}$, que, por sua vez, são os que mais resistem ao modelo, segundo afirmação do próprio autor (Gomes). 
Figura 2: Adaptação às dimensões da resistência em EaD para UC de Gomes (2008)

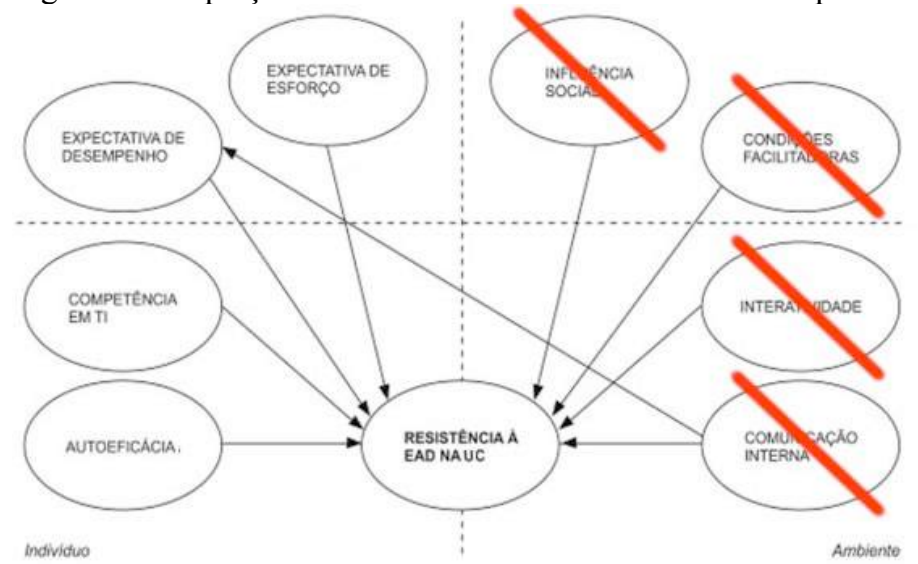

Fuente: Adaptação de Viana, 2011.

Assim, as dimensões não ligadas à ambiência, que se constituem, portanto, nos motivadores mais recorrentes de resistência, na observação de Gomes (2008) e Viana (2011) são:

Figura 3: Principais dimensões da resistência
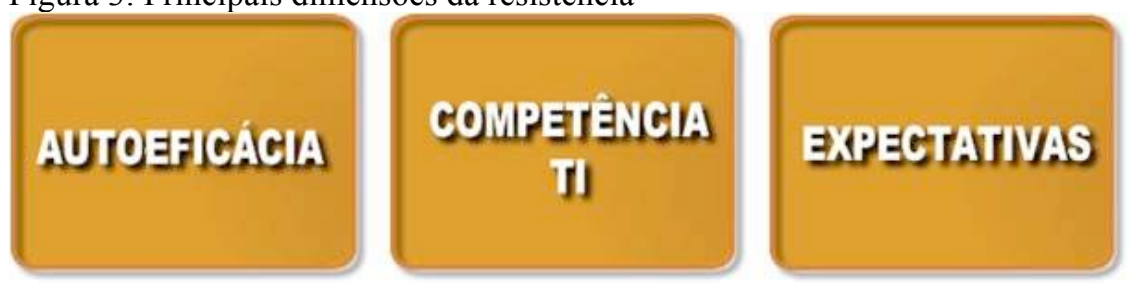

Fonte: Viana, 2011.

Autoeficácia: capacidade do indivíduo de autocondução de um sistema. Competência em TI: intimidade do indivíduo com elementos tecnológicos. Expectativas: expectativa de desempenho + expectativa de esforço.

\section{Marketing Digital estratégico em rede social na tentativa de redução da re- sistência à Educação a Distância: um estudo de caso do Facebook da Fundação Cecierj}

\subsection{O valor percebido em Marketing e as expectativas sobre a EaD}

Com base nas considerações acadêmicas acerca da Educação a Distância e os motivos que levam a sua resistência, como na América Latina, o artigo apresenta um estudo de caso.

Trata-se do Facebook da Fundação Cecierj - Centro de Ciências e Educação Superior a Distância do Rio de Janeiro - Brasil, na abordagem das estratégias de Marketing Digital utilizadas pela instituição na tentativa de reduzir a resistência à Educação a Distância junto a seu público que, em junho de 2014, somam 75 mil pessoas, que espontaneamente aderiram à página. O Facebook Cecierj é uma das maiores redes sociais do Governo do Estado do Rio e está entre as maiores em Educação Pública do Brasil.

A Fundação é, portanto, um órgão governamental, cuja área de atuação é a EaD, sendo a instituição responsável por coordenar, nesta modalidade, cursos de graduação de oito universidades públicas do Estado do Rio, que, juntas, reúnem 40 mil alunos matriculados nas carreiras ofertadas no modelo a distância de ensino. 
Rumo ao objetivo apresentado, uma das bases que norteiam as ações de Marketing Digital no Facebook da instituição é o estudo dos motivos que levam à resistência, sendo os principais deles, como visto: autoeficácia, competência em TI e expectativas.

As variáveis de autoeficácia e competência em TI não são possíveis mensurar no público do Facebook da Fundação Cecierj, uma vez que são habilidades inerentes ao indivíduo. No entanto, suas expectativas frente ao tema da Educação a Distância são previsíveis e entendidas como parte do contexto histórico e sócio-cultural a que está inserido, conforme abordado neste artigo. Assim, as expectativas constituem-se a dimensão apropriada para abordar a resistência na análise da rede social em questão.

Figura 4: Adaptação dos autores deste artigo às principais dimensões da resistência de Viana (2011), para análise da atuação do Marketing Digital no Facebook da Fundação Cecierj
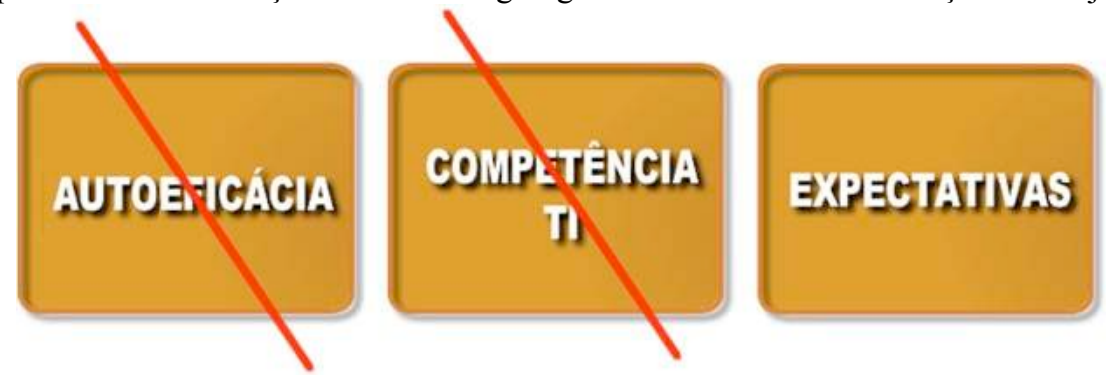

Fonte: Elaboração própria, 2014.

Ao conhecimento dos mecanismos que levam à tal resistência, somam-se estudos acadêmicos em Marketing, que completam o arcabouço teórico utilizado para a análise do objeto de estudo. Primeiramente, para adequar a linguagem à área, leva-se em conta que a mensagem a ser transmitida pela instituição na rede social é o produto, sendo, no caso em questão, toda informação que busque minimizar a resistência à EaD. Na sequência, aquele que se pretende atingir, ou seja, o público do Facebook, é o cliente ou consumidor.

Um estudo sobre o valor percebido de um produto em Marketing, segundo Kotler (1998), aponta que este é o resultado da diferença entre o valor total esperado e o custo total envolvido na transação. Veja Figura 5:

Figura 5: Teoria do valor percebido de um produto

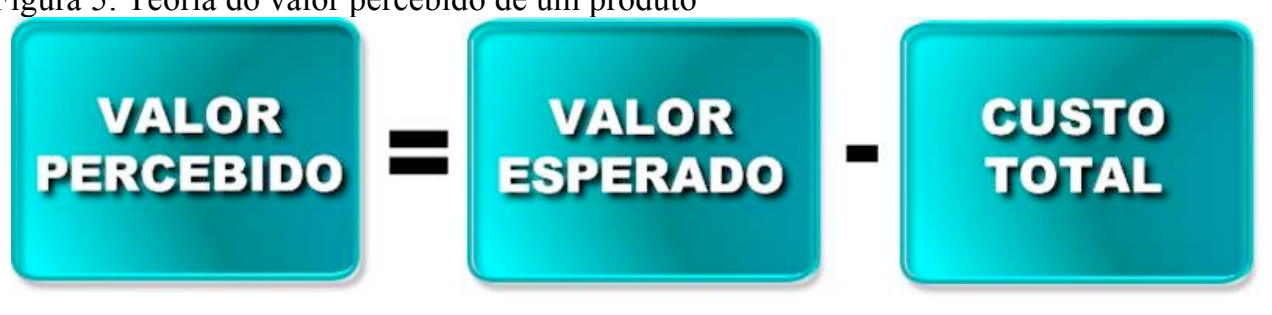

Fonte: Kotler, 1998.

Por exemplo: espera-se que um produto X custe 100 dólares, pela qualidade que o consumidor espera dele e acredita que ele possua. Mas, efetivamente, o produto custa 50 dólares. $\mathrm{O}$ valor percebido tem saldo positivo: valor esperado (100) - custo total (50). Ou seja, o produto X tem uma imagem positiva junto ao consumidor. Porém, suponhamos o inverso: é esperado que o produto $\mathrm{Y}$ custe 50 dólares, mas, concretamente, custa 100. Neste caso, é negativo o valor que cliente percebe o produto.

Y, pois ele atribui que sua qualidade valha 50, no entanto, terá que pagar 100 se quiser adquiri-lo.

Todavia, o produto em questão neste artigo, isto é, a mensagem veiculada no Facebook, não envolve custo de venda, dando origem ao seguinte esquema adaptado, conforme Figura 6: 
Figura 6: Adaptação dos autores deste artigo à teoria de Kotler (1998) do valor percebido de um produto

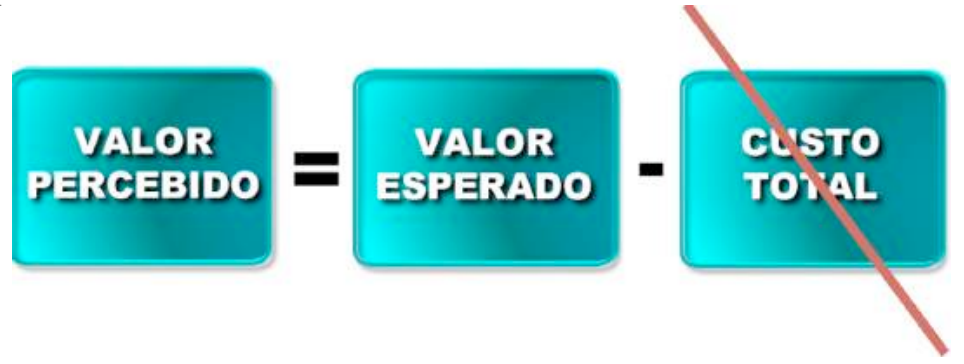

Resultado da eliminação do custo total:

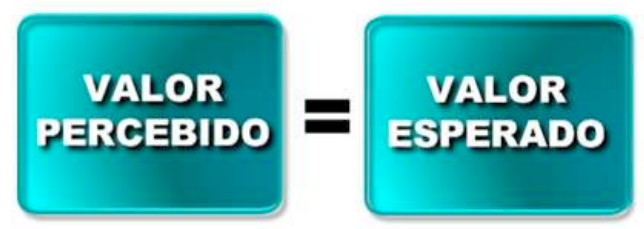

Fonte: Elaboração própria, 2014.

Deste modo, no trabalho de Marketing que envolve o Facebook da Fundação Cecierj, no objetivo de reduzir a resistência à Educação a Distância perante seu público, o valor percebido é igual ao valor esperado.

Por analogia, pode-se considerar que a adaptação deste artigo à percepção do produto de Kotler (valor percebido $=$ valor esperado), equipara-se a uma das principais dimensões da resistência na teoria de Gomes (expectativas), única a ser levada em conta para análise da atuação do Marketing na rede social, objeto deste estudo. Veja Figura 7:

Figura 7: Analogia dos autores do artigo entre as adaptações da percepção do produto no Marketing - Kotler (1998) e dimensão da resistência - Gomes (2008)

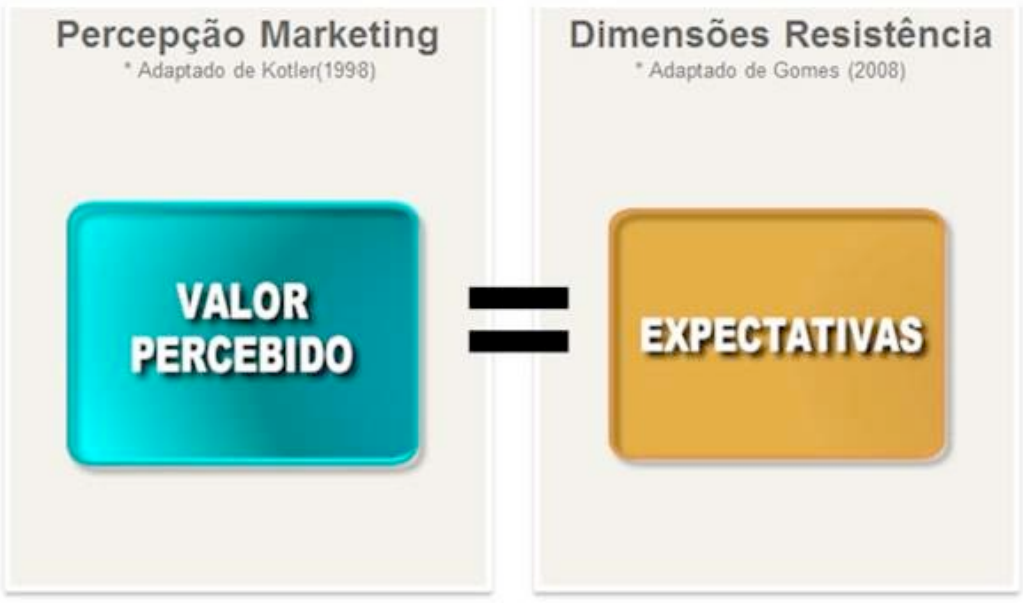

Fonte: Elaboração própria, 2014.

Pelos estudos apresentados neste trabalho, sabe-se do destaque que expectativas negativas assumem na Educação a Distância no Brasil. Diante disso e baseado na analogia elaborada, para que o indivíduo mude suas expectativas, é necessário, por meio do Marketing, estimulá-lo a alterar seu valor percebido ou valor esperado, em relação à $\mathrm{EaD}$, de negativo para positivo. 


\subsection{O Marketing 3.0}

Segundo Kotler et al. (2010), o Marketing é um processo social e gerencial, através do qual indivíduos e grupos obtêm o que necessitam e desejam por meio da criação e troca de produtos e valores com outras pessoas, buscando o mercado suprir a demanda de produtos e serviços.

O conjunto das ideias de ver o mundo de cada ser social forma as representações coletivas, que são objetivas, pois já passaram pela discussão e aprovação dos indivíduos com suas subjetividades, e chegou-se a um senso comum, podendo assim ser generalizada, tal como considera Moscovici (2002). Nesse sentido, para o autor, o Marketing tem a característica de contribuir para a formação do pensamento coletivo.

Para proporcionar a mudança na potencial percepção negativa do produto (a $\mathrm{EaD})$, por parte do público do Facebook Cecierj, os gestores da página lançam mão do Marketing 3.0, um modelo de Marketing que prima pela interação humanizada com o cliente, para que a mensagem atinja não só a mente, como também o coração e o espírito do consumidor, como elucida Kotler (1998). É exatamente neste ponto da humanização que este modelo se diferencia dos demais.

A evolução do Marketing passou por três fases, nas quais se evidenciam os modelos 1.0, $2.0 \mathrm{e}$ 3.0, de acordo com o autor. No primeiro deles, surgido na Revolução Industrial, com o desenvolvimento da tecnologia de produção, as ações de Marketing eram centradas nos produtos. Estes eram básicos, padronizados, para servir a massa de consumidores.

Os custos de produção eram reduzidos para baixar ao máximo o preço dos produtos e, assim, obter ganho em larga escala. Neste contexto, ficou famosa a frase de Henry Ford: "O carro pode ser de qualquer cor, desde que seja preto". A tarefa do Marketing era simples, pois não comportava interação com o cliente.

Na sequência, o Marketing 2.0 surgiu na atual era da tecnologia da informação, com a grande difusão da internet. Neste modelo, o cliente é o foco das ações. Os produtos passam a ser variados para servir consumidores bem informados e, por consequência, cada vez mais exigentes, que expõem seus desejos e necessidades. O profissional de Marketing, conforme Kotler et al. (2010), tinha a tarefa de chegar à mente e ao coração do consumidor.

Hoje, observamos o aparecimento do Marketing 3.0 ou era voltada para os valores, segundo o autor. O ser humano, com sua sensibilidade, torna-se o centro das ações, para o qual os produtos são pensados e desenvolvidos visando atingi-lo em um nível mais profundo, que tenha a ver com sua essência e provoque emoções. Kotler et al. (2010) criou os chamados 4 Ps que orientam as ações de Marketing, sendo produto, preço, ponto e promoção. Mais tarde acrescentou outro $\mathrm{P}$ à lista: o de Pessoas, dada a importância da humanização na prática do Marketing, em nome da eficiência.

Cada vez mais o ser humano busca satisfazer seus anseios de justiça social, econômica e ambiental, que fazem parte das ansiedades coletivas por um mundo melhor. Kotler et al. (2010) comenta que o Marketing 3.0 atua na nova onda de tecnologia, que permite e facilita a conectividade e interatividade entre indivíduos e grupos.

As empresas que praticam o Marketing 3.0 têm uma contribuição maior em termos de missão, visão e valores a apresentar ao mundo; seu objetivo é oferecer soluções para os problemas da sociedade, (...) com respostas e esperança às pessoas que enfrentam esses problemas e, assim, tocar os consumidores em um nível superior. (Kotler, 2010, p. 5)

Ao contrário do modelo 2.0, neste, o consumidor é ativo e os produtos passam a ser também notícias, ideias e entretenimento. Kotler et al. (2010) entende o modelo 3.0 como uma mescla de Marketing Colaborativo, Cultural e Espiritual. O primeiro deles reflete a chamada era da participação, em que os consumidores deixam de ser indivíduos isolados e passam a se conectar uns aos outros. Tal mudança é possibilitada pelos avanços tecnológicos, pelas mídias sociais e mídias colaborativas, como Wikipedia, Rotten Tomatoes e Craiglist, que permitem a troca de informações, em ambientes alimentados pelos próprios usuários. 
A crescente tendência à existência de consumidores colaborativos afetou os negócios. Hoje, os profissionais de marketing não têm mais controle de suas marcas, pois agora estão competindo com o poder coletivo dos consumidores (...) As empresas agora precisam colaborar com eles. A colaboração começa quando os gerentes de marketing ouvem a voz do consumidor para entender sua mente e captam insights do mercado. Ocorre uma colaboração mais avançada quando os consumidores desempenham o papel principal na geração de valor por meio da cocriação de produtos e serviços. (Kotler et al., 2010, p. 11)

Para Kotler et al. (2010), as empresa que adotam o conceito 3.0 de Marketing querem mudar o mundo para se adequarem a este mesmo desejo social da atualidade. Porém, não conseguirão fazer isso sozinhas. Daí a relevância das cocriações, termo criado por C.K. Prahalad para designar a participação do cliente na criação de produtos. "A experiência de um produto jamais é isolada. (...) Quando os consumidores individuais experimentam o produto, personalizam a experiência de acordo com necessidades e desejos singulares." (Kotler et al., 2010, p. 37)

$\mathrm{O}$ consumidor tende a valorizar e dar mais atenção às ideias e experiências de outros consumidores do que ao discurso da própria marca. Assim, entendendo esta dinâmica, as empresas que aplicam o 3.0 buscam se valer do Marketing Colaborativo, estimulando no cliente o despertar da cocriação e seu posterior desenvolvimento e produção por parte da empresa.

O Marketing Cultural, como parte do modelo 3.0, compreende as ações que são desenvolvidas em constante atenção aos contextos político, econômico e social, no que tange o global e o local. São estratégias que abordam os paradoxos da globalização, conforme aponta o autor, como na exaltação de uma marca local, frente a marcas globais e vice-versa. A aplicação do Marketing Cultural aproxima os consumidores da marca, na medida em que se cria uma identidade com suas experiências, valores, modo de vida etc.

É nessa linha de raciocínio que o Marketing 3.0 estabelece relação ainda com o Marketing Espiritual, quando a missão, a visão e os valores são abordados junto ao cliente, buscando atingi-lo profundamente. É com mais esse ponto que a área explora o $\mathrm{P}$ de pessoas nomeado por Kotler (2010), moldando, assim, os princípios do Marketing de Relacionamento, tão essencial nos dias atuais para uma comunicação eficaz na área.

"Marketing de Relacionamento é o processo de estabelecer e manter relacionamentos de longo prazo mutuamente benéficos entre organizações e seus clientes, empregados e outros grupos de interesse". (Nickels e Wood, 1999, p. 5) O foco é estabelecer relacionamentos duradouros entre marca e cliente, empresa e consumidor. Segundo os autores, isto é possível não somente quando as partes mantêm contato, mas quando a interação é baseada na confiança.

Tal confiança é alcançada com permanente atenção aos questionamentos, sugestões e intervenções do consumidor, não o deixando sem resposta nos espaços de interação. Primar pelo tratamento personalizado e individualizado é um dos princípios do Marketing de Relacionamento, nomeado de Nanotarget, de acordo com Kotler et al. (2010).

Técnicas de Nanotarget incluem, por exemplo, chamar o indivíduo pelo nome, o que desperta sua atenção e o faz sentir-se prestigiado, único, exclusivo; sentimento que pode ser ainda mais ressaltado no público com mensagens especialmente focadas em cada caso que surge em busca de solução, sendo uma dúvida, uma reclamação ou um elogio. Estas são formas de aproximar o cliente para a construção de relacionamentos sólidos entre público e marca.

\subsection{O Marketing 3.0 e as redes sociais}

Nas elucidações acerca do modelo de Marketing 3.0, vale destacar as mídias sociais expressivas como novas formas de comunicação e ferramentas de aplicação, no ambiente digital, das estratégias detalhadas anteriormente.

Desde 2000, podemos perceber que a tecnologia da informação penetrou no mercado, transformando as formas de interação entre as pessoas e como elas se relacionam com as empresas. A comunicação agora tem mais conectividade e mobilidade, pois temos quatro grandes forças que são os pilares da nova onda da tecnologia: os computadores e celulares cada vez mais acessíveis, a internet de baixo custo, a fonte aberta e o wi-fi revolucionando a acessibilidade e a mobilidade. (Gomes e Curi, 2013) 
As mídias sociais ascenderam e mudaram a forma das pessoas se relacionarem. Para Gomes e Curi (2013), os ambientes virtuais tornaram-se o novo espaço de convivência das pessoas, e já são chamadas de as novas praças, ruas, ou qualquer espaço que faz parte da esfera pública. Isso ocorre porque, hoje, qualquer informação pode ser processada e redistribuída em formato digital, havendo assim muitos métodos e maneiras de expansão.

O Marketing Digital vem atuar nesse lugar. O que antes era, em sua grande maioria, mídia de massa, hoje é mídia segmentada. Segundo Gomes e Curi (2013), houve uma inversão na comunicação e todo processo de comunicação agora deverá começar pelo público-alvo, com profissionais de Marketing buscando atuar da maneira mais focada e econômica possível em relação a seu consumidor, sabendo quem ele é e quais são seus desejos e anseios, agregando valores de um mundo melhor e usando estratégias com precisão.

Recuero (2009) e Lin (2001) afirmam que as mídias sociais permitem o acúmulo de capital social, um conceito metafórico que foca o fato de que existem vantagens em pertencer a grupos sociais. Os compartilhamentos, que compõem as trocas de informações, constituem o grande investimento e ganho das empresas, por meio do crescente número de pessoas conhecendo e dividindo ideias e valores da marca, estando, neste contexto, a atuação do Marketing de Relacionamento na construção de relacionamentos duradouros.

Merece destaque ainda o controle de marketing, por meio de constante monitoramento, com plataformas específicas para o trabalho, além de verificação constante de conteúdo, pesquisas, métricas e estatísticas de acessos e compartilhamentos. Para Torres (2009), tais procedimentos auxiliam na pesquisa do público-alvo e direcionam as ações na área.

\subsection{As aplicações do Marketing 3.0 no Facebook da Fundação Cecierj}

No universo das redes sociais, o Facebook é destaque no Brasil. Com 76 milhões de usuários, segundo a plataforma de gerenciamento de redes sociais - Scup, é o vice-líder mundial de participantes na rede. Considerando que o país tem cerca de 190 milhões de habitantes, de acordo com o IBGE (2010), pode-se dizer que mais de um terço da população brasileira acessa o Facebook.

Diante de expressiva mídia social, a Fundação Cecierj a adotou (facebook.com/cecierj) como ferramenta de aplicação das estratégias de Marketing apontadas neste estudo, rumo a seu objetivo: tentar reduzir a aparente resistência em relação à Educação a Distância para uma eficaz de venda de seu produto: a EaD.

A página da rede social em questão foi observada de maio de 2012 a fevereiro de 2014, no que tange a suas postagens, por meio de campanhas publicitárias, e a suas formas de interação, como na linguagem adotada.

Cabe destacar a importância dada pela empresa para a pesquisa de seu público-alvo, como parte do Marketing Digital estratégico. Saber o que pensa o cliente é essencial e, para isso, a Cecierj se vale do estudo acerca dos porquês da resistência à $\mathrm{EaD}$, conforme visto, a qual seu público está potencialmente sujeito.

Como o modelo de gestão de Marketing utilizado é o 3.0, a instituição orienta suas ações com aplicações de Marketing Colaborativo, Cultural e Espiritual, sob os pilares do Marketing de Relacionamento.

O Facebook da Fundação Cecierj tem três anos de existência e cinco estrelas na avaliação do público. Chamados de fãs pelo próprio sistema da rede social em questão, as 75 mil pessoas que integram a página são, principalmente, alunos e ex-alunos de $\mathrm{EaD}$, das universidades cujos cursos a distância são coordenados pela Fundação; e também aspirantes a uma vaga.

No trabalho de Marketing Digital nesta rede, o órgão lança mão, diariamente, de técnicas de Marketing de Relacionamento na interação com o cliente, usando tratamento diferenciado para cada usuário, com foco em cada problema, beneficiando-se da boa impressão causada por uma abordagem individualizada, como já apontado. Assim, a imagem da instituição ganha credibilidade na rede, e por consequência, suas mensagens também são tomadas como confiáveis.

É nesse momento que a instituição utiliza seu poder de persuasão com o benefício da identidade estabe- lecida entre público e marca, fazendo as ideias e os valores atrelados à qualidade da 
Educação a Distância serem mais facilmente assimilados, ganhando também a simpatia do interlocutor. Veja Figura 8:

Figura 8: Marketing de Relacionamento (Nanotarget) e sua aplicação

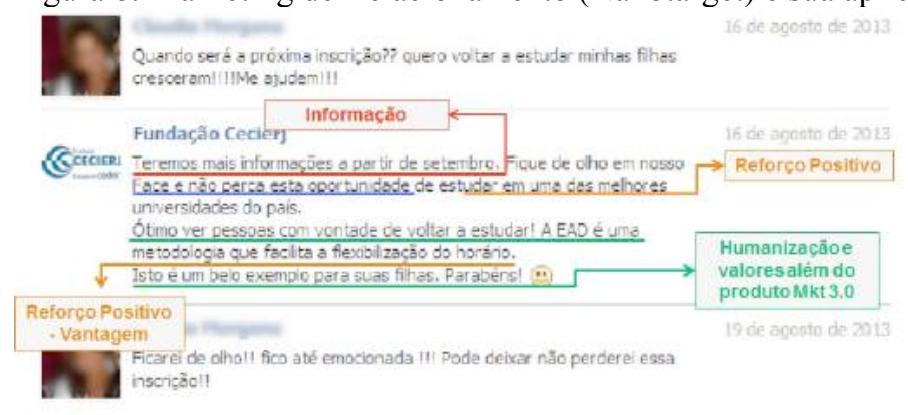

Fonte: Facebook Fundação Cecierj-publicado em 16/03/2013.

No exemplo da Figura 8, a pergunta da participante da página estaria satisfatoriamente respondida apenas com a primeira frase. No entanto, ao praticar o Marketing 3.0, a Fundação Cecierj preocupou-se em aproveitar a oportunidade de interação para transmitir uma mensagem positiva, ao mesmo tempo em que valoriza a Educação a Distância, ainda que a interlocutora não tenha feito menção ao assunto.

Assim, o órgão utiliza este espaço de pergunta e resposta para vender o seu produto (EaD), ao tentar intervir na expectativa que esta pessoa do público possa ter em relação à metodologia de ensino a distância, que, como se sabe pelos estudos, é potencialmente negativa. A resposta humanizada, de apoio e incentivo no caso do exemplo, completa a abordagem do modelo 3.0 adotado.

O diálogo da Figura 8 ilustra a aplicação do Nanotarget, um dos princípios do Marketing de Relacionamento, ao interagir com a integrante da página de modo particular, sensível às questões por ela comentadas, com tratamento o mais personalizado possível.

A Fundação Cecierj, em seu Facebook, também elabora campanhas publicitárias que criem engajamento com o público. Valendo-se da teoria do Marketing Colaborativo, um dos pilares do modelo 3.0, foi desenvolvida uma campanha de perguntas ao público para que este pudesse participar em conjunto com a rede, enviando sugestões de assuntos de interesse que gostaria de encontrar na página, fazendo-o se sentir participativo e coautor daquele espaço, como no exemplo a seguir (Figura 9):

Figura 9: Aplicação de Marketing Colaborativo

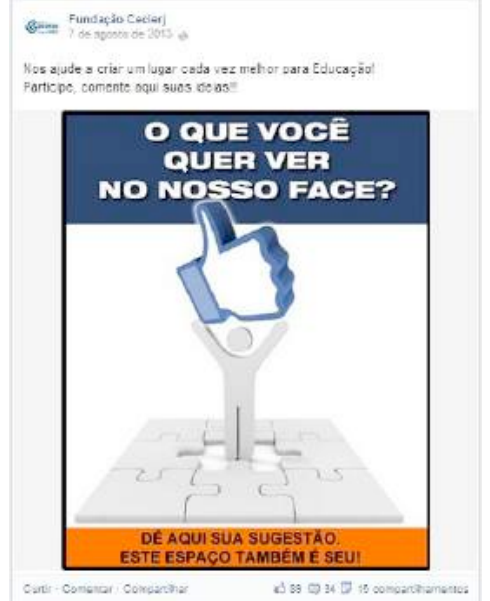

Fonte: Facebook da Fundação Cecierj - Publicado em 7/08/2013. 
Com esta campanha, centenas de pedidos e sugestões do público foram postados na rede social da instituição, sendo muitas delas, acatadas e veiculadas, como na Figura 10, que atende a solicitações para que fossem disponibilizados cursos de informática na página, o que se aproxima de um dos motivos estudados que levam à resistência à $\mathrm{EaD}$ : as dificuldades em se lidar com o campo da informática.

Figura 10: Aplicação de Marketing Colaborativo, por meio de Cocriação

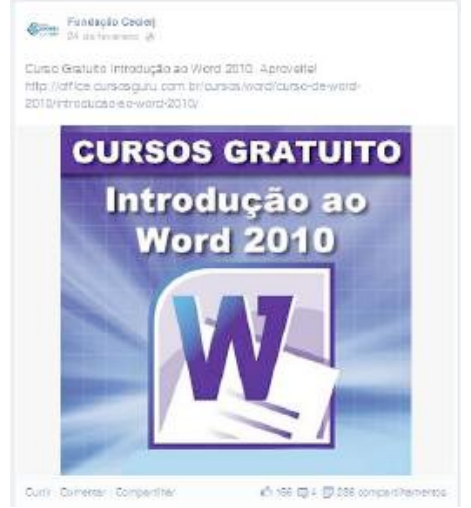

Fonte: Facebook da Fundação Cecierj-Publicado em 24/02/2014.

Com a postagem, o órgão incentivou, desenvolveu e viabilizou as cocriações, ferramenta do Marketing Colaborativo, fazendo os participantes do Facebook Cecierj se sentirem prestigiados, com voz ativa e pertencentes a um espaço digital amigável, interativo e acolhedor.

Esta estratégia de proporcionar identidade e bom relacionamento do público com a empresa cria ambiente propício para a transmissão de mensagens com eficaz assimilação e aceitação das mesmas. Ou seja, com os mecanismos de Marketing apresentados, a Cecierj está propensa a uma boa receptividade das mensagens que estimulem a redução da resistência à $\mathrm{EaD}$, como nas outras ilustrações que se seguem.

Atento ao contexto social brasileiro, de potencial resistência ao modelo de ensino a distância, a empresa utiliza também o Marketing Cultural, outro princípio do 3.0. Uma campanha publicitária que ilustra tal ação é a utilização da figura de Nelson Mandela na propagação de que a metodologia de ensino pode ser de qualidade e confiável, já que o líder sul-africano cursou graduação a distância, assim como outras figuras globais de renome. (Veja Figura 11):

Figura 11: Campanha publicitária de promoção da EaD
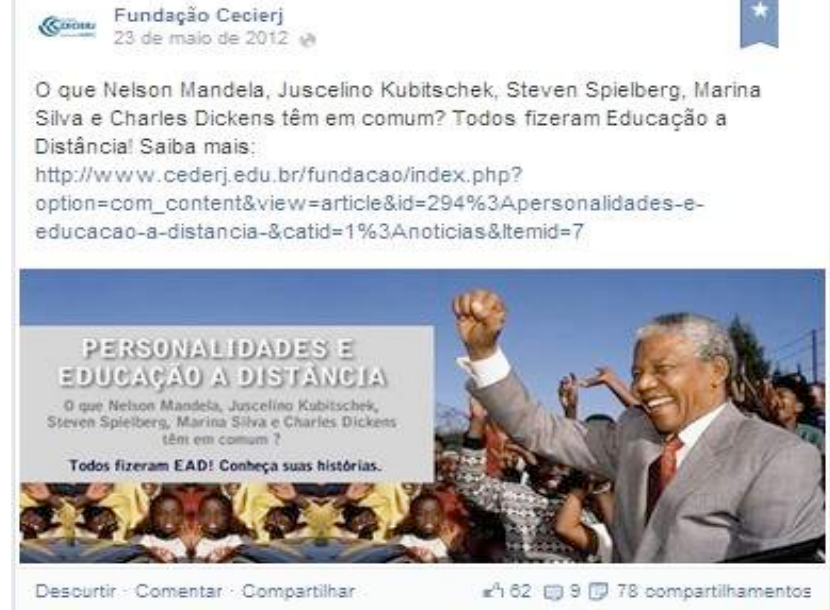

Fonte: Facebook Fundação Cecierj-publicada em 23/05/2012. 
O trabalho de Marketing inclui também a adoção de frases que valorizam a Educação e a Educação a Distância, mencionadas por pensadores de renome como o ícone da área, Paulo Freire (Veja Figura 12):

Figura 12: Campanha publicitária de promoção da EaD

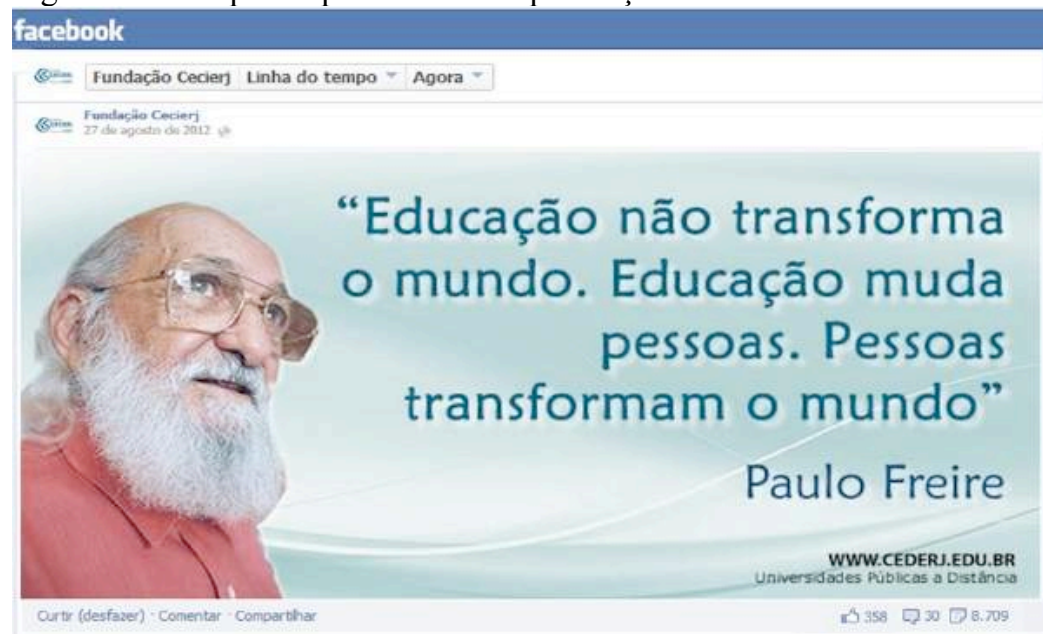

Fonte: Facebook Fundação Cecierj-publicada em 27/08/2012.

Com postagens deste tipo, busca-se alcançar credibilidade junto ao público, ao demonstrar sintonia com personalidades consagradas da área. Conforme exposto na Figura 12, esta campanha com Paulo Freire teve mais de 8 mil compartilhamentos, o maior índice já alcançado na página, o que motivou a instituição a utilizar outras vezes veiculações deste tipo.

Desta forma, com elevado engajamento da mensagem, a instituição se beneficia do acúmulo de capital social, como já elucidado neste artigo, segundo Recuero (2009) e Lin (2001). Quando pessoas compartilham uma postagem, fazem repercutir também a marca, com suas ideias e conceitos, gerando propaganda, motivo para assunto na rede, o que, para o Marketing, é ganho fundamental.

Outras campanhas no Facebook reforçam positivamente a qualidade das universidades públicas que oferecem as graduações a distância coordenadas pela Cecierj. Veja Figura 13:

Figura 13: Campanha publicitária de boas-vindas aos aprovados no vestibular das universidades públicas a distância no Estado do Rio de Janeiro

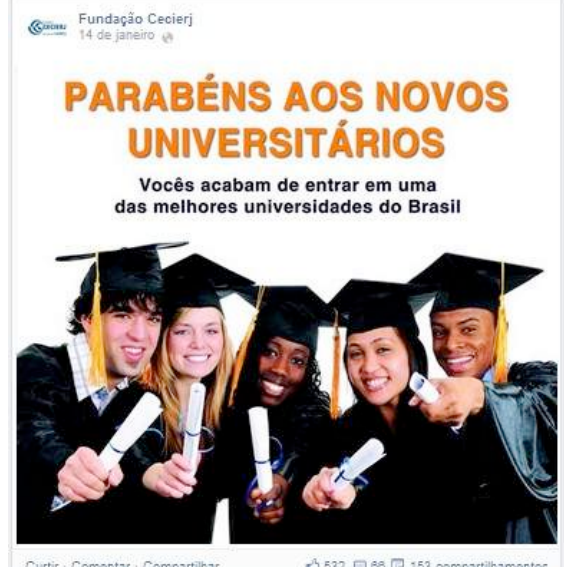

Fonte: Facebook Fundação Cecierj - publicada em 14/01/2014. 
As universidades em questão possuem graduações nas duas modalidades: presencial e a distância. Pelos questionamentos recebidos no Facebook, é clara a observação de que alunos de EaD e/ou candidatos a uma vaga têm receios quanto ao modelo a distância e indagam, por exemplo, se o seu diploma tem o mesmo valor do diploma no método presencial.

Identificada a resistência, a campanha da Figura 13 busca minimizar este temor, e faz uma abordagem aos universitários sem mencionar a $\mathrm{EaD}$, demonstrando a qualidade das universidades sem distinção de metodologia. Este é um exemplo de aplicação do Marketing Espiritual, quando se busca atingir o indivíduo profundamente, no ponto exato daquilo que ele precisa, sendo, portanto, o terceiro e último pilar do Marketing 3.0, a ser abordado nas ilustrações acerca das estratégias no Facebook da Fundação Cecierj na tentativa de reduzir a resistência à Educação a Distância.

\section{Considerações finais}

O estudo não tem intenção de mostrar se os integrantes da página de fato alteraram suas percepções desfavoráveis ao ensino a distância. Entretanto, é relevante observar que o público geral da empresa pública em questão possui, em seu Facebook, uma percepção positiva desta instituição de EaD na rede, mesmo em meio à negatividade que permeia a Educação a Distância no conceito de seu público-alvo.

Sendo uma das maiores redes sociais em Educação Pública no Brasil, o Facebook Cecierj é destaque em número de participantes, interação e engajamento, apesar de sua temática não favorecer simpatia, credibilidade e adesão a um espaço virtual.

Com este artigo, é possível observar a importância do estudo acadêmico na gestão de Marketing Digital em Facebook corporativo, para que se entenda as origens das questões-problema, sendo fundamental para o planejamento das ações que focam suas resoluções.

Portanto, são essenciais para uma comunicação estratégica eficaz com o público da rede social em questão, a identificação das causas da resistência à EaD pela teoria de estudiosos do tema e os conceitos de Marketing aplicado, a serem postos em prática por meio de campanhas publicitárias e dos espaços de interação.

Técnicas de Marketing são utilizadas por grandes corporações na venda de seus produtos, mostrando-se eficaz na construção da imagem de uma instituição e, por consequência, de suas ideias a serem expostas como objetivo de comunicação, neste caso, a inversão de percepções desfavoráveis sobre a Educação a Distância. 


\section{REFERENCIAS}

ABRAEAD (2010). Anuário Brasileiro Estatístico de Educação Aberta e a Distância 2010. São Paulo: Instituto Monitor.

Belloni, M.L. (1999). Educação a Distância. Campinas: Editora Autores Associados.

Cavalcanti, C. C. (2007). O impacto da globalização em cursos a distância na América Latina: possibilidades e riscos. XIII Congresso Internacional ABED de Educação a Distância, Curitiba.

Corrêa, S.C. e Santos, L.M.M. (2009). Preconceito e educação a distância: atitudes de estudantes universitários sobre os cursos de graduação na modalidade a distância. ETD - Educação Temática Digital, 11(1), pp. 273-297.

Costa, L.A.C. e Franco, S.R.K. (2006). Ambientes Virtuais de Aprendizagem e suas Possibilidades Construtivistas. CINTED-UFRGS: Novas CINTED-UFRGS Tecnologias na Educação. Porto Alegre.

Crochík, J.L. (2011). Preconceitos, indivíduo e cultura. São Paulo: Ed. Casa do Psicólogo.

Ferreira, A.J.N. (2010). A Educação a Distância nas Organizações: a Percepção Sobre o e-learning em uma Grande Empresa Nacional. Revista EaD em Foco, 1(1), p. 33.

Formiga, M. e Litto, F. (2009). Educação a distância: o estado da arte. São Paulo: Pearson Education do Brasil.

Gomes, M.B. (2008). Resistência à Educação a Distância na Educação Corporativa (Tese de Doutorado). Escola de Administração de Empresas de São Paulo- EAESP, FGV. São Paulo.

Gomes, M. e Kury, G. (2013). A Evolução do Marketing para o Marketing 3.0: O Marketing de Causa. Intercom - Sociedade Brasileira de Estudos Interdisciplinares da Comunicação XV Congresso de Ciências da Comunicação na Região Nordeste, Mossoró.

IBGE. Censo Demográfico 2010. Disponível em: <http://www.censo2010.ibge.gov.br>

Kotler, P. (1998). Administração de marketing: análise, planejamento, implementação e controle. São Paulo: Atlas.

Kotler, P., Kartajaya, H. e Setiawan, I. (2010). Marketing 3.0: as forças que estão definindo o novo marketing centrado no ser humano. Rio de Janeiro: Elsevier.

Lévy, P.N. (1993) As tecnologias da inteligência: o futuro do pensamento na era da informática. Rio de Janeiro: Editora 34.

Lin, N. (2001). Social capital. A theory of social structure and action. Cambridge: Cambridge University Press.

Litto, F.M. (2009). Educação a distância - O estado da arte. São Paulo: Pearson Education do Brasil. McLuhan, M. (1964). Os meios de comunicação como extensões do homem. São Paulo: Cultrix. Moore, M. (2007). Educação a Distância uma versão Integrada. São Paulo: Editora Tompson. Moran, J.M. (2009). O ensino superior a distância no Brasil. Educação \& Linguagem, 12(19), pp. 17-35. Moscovici, S. (2002). Representações sociais: a teoria e sua história. In: P. Guareschi e S. Jovchelovitch (Org.), Textos em Representações Sociais. Petrópolis, RJ: Vozes.

Nickels, G. e Wood, M.B. (1999). Marketing - Relacionamentos, Qualidade, Valor. São Paulo: Editora Ltc.

Niskier, A. (1999). Educação a Distancia - a Tecnologia da Esperança. Rio de Janeiro: Editora Loyola. Recuero, R. (2009). Redes Sociais na internet. Porto Alegre: Sulina.

Recuero, R. e Zago, G. (2011). A Economia do Retweet. Redes, Difusão de Informações e Capital Social no Twitter. Anais da XX Compós. Porto Alegre.

Recuero, R. e Zago, G. (2009). Em busca das "redes que importam": redes sociais e capital social no Twitter. Libero, 12(24), pp. 81-94.

Stone, M. e Woodcock, N. (1998). Marketing de Relacionamento. São Paulo: LitteraMundi. Schlickmann, R., Melo, P.A., Harger, C,A., Dalmau, Schoenherr, O.A.T. (2001). Cursos on-line no ensino/aprendizagem da língua estrangeira (Dissertação Mestrado). Universidade Federal de Santa Catarina. 
Toffler, A. (1997). A terceira onda. Rio de Janeiro: Record.

Torres, P.L. (2002). Laboratório Online De Aprendizagem: Uma Proposta Crítica De Aprendizagem Colaborativa Para A Educação (Tese de Doutorado). Florianópolis: Universidade Federal de Santa Catarina.

Torres, C. (2009). A bíblia do marketing digital. São Paulo: Novatec Editora.

Venkatesh, V., Morris, M.G., Davis Gordon, B. e Davis, F.D. (2003). User acceptance of Information Technology: toward a unified view. MIS Quarterly, 27(3), pp. 51-56.

Viana, G. L. (2011). Determinantes da Resistência à Educação a Distância (EAD): Uma pesquisa com alunos do Curso de Administração da UFF (Dissertação Mestrado). Universidade Federal Fluminense, Niterói.

Zaltman, G., Duncan, R. (1977). Strategies for planned change. New York: Wiley\& Sons.

Zerbini, T., Nascimento, S.B., Meneses, P.P.M. e Abbad, G. (2006). Percepções sobre Educação a Distância: Limitações e Restrições à Implantação da Universidade Corporativa do Banco Central do Brasil. Salvador: EnANPAD.

Zwicker, R. e Reinhard, N. (1997). Aprendizagem e uso de sistemas de informações: aquisição de habilidades cognitivas através de treinamento inteligente auxiliado pelo computador. Encontro anual da associação nacional dos programas de pós-graduação em administração, 17. Anais. Salvador: EnANPAD.

\section{SOBRE OS AUTORES}

Leonardo Viana: Mestre em Gestão do Conhecimento/Sistema de Gestão pela Universidade Federal Fluminense - UFF e MBA em Estratégia e Gestão. Formado em Desenho Industrial. Atua na Ciência e Tecnologia do Estado do Rio de Janeiro com portais web de grande circulação e gerenciamento de redes sociais, comunicação digital e e-Gov. Participa como coordenador de Comunicação e Marketing Digital da AIESAD (Associação Ibero-Americana de Ensino superior a Distância). Atua também como professor de pós-graduação nas áreas de Marketing Digital, Usabilidade, UX, Interface, Navegabilidade e Acessibilidade, E-commerce, Semiótica aplicada à Interface, Comunicação e Mídia, Design aplicado à Marketing na Web em instituições como Fundação Getúlio Vargas (FGV), Veiga de Almeida e Fatec. Foi coordenador de Comunicação, gerente de projetos de internet e prestou serviços em empresas como Americanas.com, BNDES, Rio+20, Gama Filho, Dominos, Apex International e Fundação Oswaldo Cruz (FIOCRUZ).

Fabiane Proba: Mestre em Comunicação pela Universidade do Estado do Rio de Janeiro - UERJ (2011), pós-graduada Latu Sensu em Comunicação Empresarial (2005) pela Universidade Veiga de Almeida e graduada em Comunicação Social, nas habilitações Publicidade e Propaganda (2004) e Jornalismo (2003), pelas Faculdades Integradas Hélio Alonso. Coordenadora de Comunicação e Marketing Digital da AIESAD (Associação Ibero-Americana de Educação Superior a Distância) e assessora de Comunicação e Marketing Digital da Fundação CECIERJ (Centro de Ciências e Educação Superior a Distância do Estado do Rio de Janeiro), órgão vinculado à Secretaria de Ciência e Tecnologia do Estado do Rio de Janeiro. Atua como assessora de Comunicação em órgãos públicos desde 2006 e foi repórter de mídia impressa por seis anos. 